\title{
Internal Fractures After Blasting Confined Rock and Mortar Cylinders
}

\author{
Ivan Kukolj', Bernd Oberdorfer², and Finn Ouchterlony ${ }^{1}$ \\ ${ }^{1}$ Chair of Mining Engineering and Mineral Economics, Montanuniversitaet Leoben, Leoben, Austria \\ ${ }^{2}$ Österreichisches Gießerei Institut (ÖGI), Montanuniversitaet Leoben, Leoben, Austria
}

Received August 29, 2019; accepted September 2, 2019; published online September 23, 2019

\begin{abstract}
Blast-induced fines in rock negatively influence multiple aspects of raw-mineral sustainability. The Austrian Science Fund (FWF) sponsored a project to investigate the cause of the fines by studying blast fragmentation through small-scale blast tests and numerical simulations. The paper covers the experimental part of the project focusing on internal blast-induced fracturing and related mechanisms. The blast tests were done by blast-loading confined granite and mortar cylinders. The blast-driven dynamic cracking at the end face of the cylinder opposite to the initiation point was filmed with a high-speed camera. Following analyses covered internal crack patterns, fracture surfaces, and sieving of the blasted cylinders to quantify the amount of fine material created. The internal crack patterns and fracture surfaces were analysed by means of computer tomography (CT) and scanning-electron microscopy (SEM). The CT scans show that the amount of explosive charge affects the changing of the topological features of the crack patterns along the cylinder. They also depict different deformation zones around the blast-hole wall with respect to the blasted material and the amount of charge. Although fracture surfaces of larger fragments do not clearly differ in measured roughness and curvature, the SEM scans of smaller fragments show clear difference in fracture surfaces with respect to the blasted material and the amount of charge. SEM scans of thin sections extracted from the blasted cylinders show different fracture features that could be related to the branching/merging mechanism.
\end{abstract}

Keywords: Blast-induced fines, Blast tests, Dynamic fracturing, Crack patterns, Fracture surface, CT, SEM

\footnotetext{
I. Kukolj, MSc. ( $\square)$

Chair of Mining Engineering and Mineral Economics,

Montanuniversitaet Leoben,

Erzherzog-Johann-Straße 3,

8700 Leoben, Austria

ivan.kukolj@unileoben.ac.at
}

Interne Rissbildung nach der Sprengung von abgegrenzten Gesteins- und Mörtelzylindern

Zusammenfassung: Bei Gesteinssprengungen entstehende, nicht verwertbare Feinanteile haben oft einen negativen Einfluss auf Umwelt, Nachhaltigkeit und Wirtschaftlichkeit. Der Österreichische Wissenschaftsfonds (FWF) fördert ein Projekt zur Untersuchung der Ursache von Feinanteilen mittels Analyse der Zerkleinerung bei Sprengversuchen in kleinem Maßstab und mittels numerischer Modellierung. Der Beitrag behandelt den experimentellen Teil des Projekts, der sich auf die internen sprenginduzierten Risse, Bruchvorgänge und Mechanismen konzentriert. Die Sprengtests wurden an Granit- und Mörtelzylindern durchgeführt, die über eine damit verbundene zentrale Bohrung gesprengt wurden. Die sprenginduzierte dynamische Rissbildung an der dem Einleitungspunkt gegenüberliegenden Stirnseite des Zylinders wurde mit einer Hochgeschwindigkeitskamera aufgenommen. Darauf folgten Analysen der inneren Rissstrukturen und Bruchflächen sowie eine Siebanalyse, mittels derer die Korngrößen der gesprengten Zylinder untersucht wurden, um die Masse des erzeugten Feinmaterials zu quantifizieren. Die internen Rissmuster und Bruchflächen wurden mittels Computertomographie (CT) und Rasterelektronenmikroskopie (REM) analysiert. Die CT-Untersuchungen zeigten, dass die Größe der Sprengladung beeinflusst, wie sich die topologischen Eigenschaften der Rissstrukturen entlang des Zylinders verändern. Sie zeigen auch unterschiedliche Verformungszonen um die Bohrlochleibung. Obwohl sich die Bruchflächen größerer Fragmente in Rauigkeit und Krümmung nicht wesentlich unterschieden, wiesen die REM-Aufnahmen kleinerer Fragmente einen deutlichen Unterschied der Bruchflächen wiederum abhängig von Material und Sprengladung auf. REMAufnahmen von Dünnschliffen, entnommen aus den gesprengten Zylindern, zeigten verschiedene Bruchmerkmale, die auf den Verzweigungs-/Vereinigungsmechanismus hinweisen. 

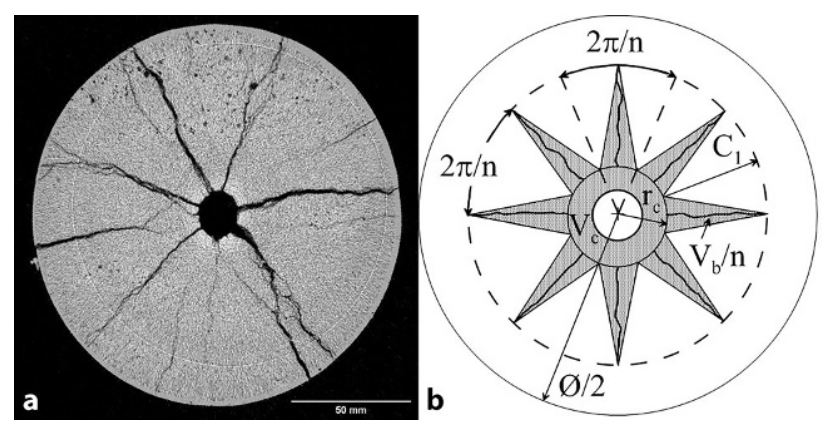

Fig. 1: Comparison of blast-induced crack patterns in post-mortem mortar cylinder (12 g/m PETN (b/21)) with the star-shaped CZM

Schlüsselwörter: Sprenginduzierte Feinanteile, Sprengversuche, Dynamische Rissbildung, Bruchfläche, CT, SEM

\section{Introduction}

Fines are the size fraction of fragmented material below a certain exploitation limit. Fines as waste are mostly produced by blasting, along with crushing and milling. Blast fines therefore negatively influence cost and revenue, environment and health protection, and sustainability related to extraction of raw minerals [1-3].

Blasting is a highly dynamic process and the crack growth that defines breakage is considered a major source of fines [4]. Such crack-generated fines (CGF) are also produced by crushing and grinding, and they are inherently related to the amount of energy required in comminution. Most of the area created resides in the fines and this area then determines the energy consumed [5]. A better understanding of how CGF are generated could help to improve blasting and crushing practices, e.g., by suppressing the amount of CGF at the source rather than dealing with them afterwards.

Blast-induced fines, however, are often considered to originate mainly from the crushed zone around the blast hole $[6,7]$. Related models imply that fragment size is mostly defined by the distance to the blast source, creating the finest material at the blast-hole wall and increasingly larger fragment sizes with distance from the blasthole. This approach, applied through the circular crushedzone model (CZM), has been extended into the star-shape model ([8]; Fig. 1b), thus, including the CGF to some extent.

Blasting tests with layered cylinder specimens $[9,10]$ contradict the predictions of the star-shaped CZM, suggesting higher importance of propagating cracks in the generation of fines.

Real post-mortem crack patterns are far more complex than in the CZM (Fig. 1a). In blasted rock samples, the crack propagation direction changes, and cracks branch and merge, forming smaller fragments. Therefore, the patterns should include information on the CGF.

The blast-generated fracture surfaces are also likely to contain information on the mechanisms that produce the fines [4]. In many materials, the surface roughness of prop-

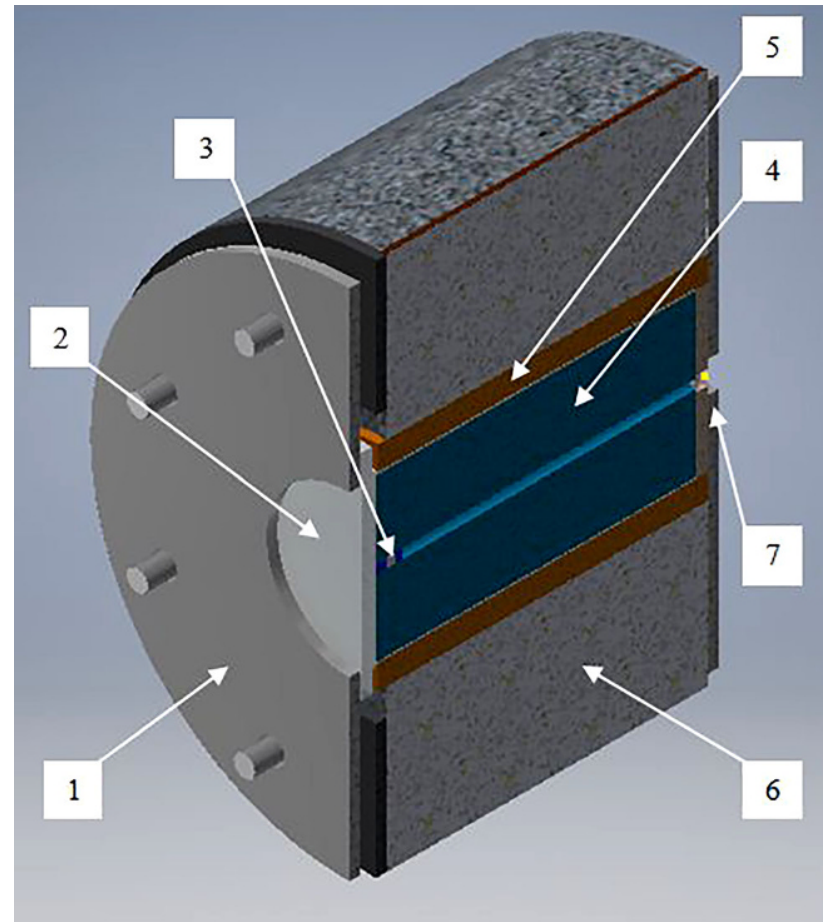

Fig. 2: Prepared blast chamber (axial cross-section) (1-Frontal end metal plate;2-Protectivewindow;3-Boreholewith stemming;4-Blast cylinder; 5-Damping layer; 6-Chamber segment; 7-Rear-end metal plate)

agating fractures is related to loading rate and crack speed, or rather, to the stress intensity factor in brittle solids [11].

The mechanism of branching/merging of a dynamically propagating crack tip has been proposed as the dominating source of CGF $[4,12,13]$. This lead to the FWF project P27594-N29 "Fines generated by dynamic crack propagation, as in blasting of rock-like materials."

Following an analysis of the high-speed images of the cylinder's frontal end face and further analyses of the crack patterns and fracture surfaces inside, the cylinders were pried open for fragmentation analyses and to determine the source mechanisms of the fines.

This paper presents the latest findings from the experimental part of the project. More results and methodology descriptions may be found in Kukolj's PhD thesis [14].

\section{Methodology}

\subsection{Small-Scale Blast Tests}

The blast tests $[10,15]$ included blasting of confined cylinders of mortar or granite, $\varnothing 150 \times 300 \mathrm{~mm}$ in size, with a $\varnothing 10$-mm central axial borehole. The blast-driven cracking was filmed at its frontal end face by means of highspeed filming [15].

The blasting included a fully-decoupled PETN (Pentaerythritol tetranitrate) cord $(6,12$, or $20 \mathrm{~g} / \mathrm{m})$ inside the borehole. Such charge amounts were chosen to observe the transition from the blasting below the critical level with "dust and boulders" $[4,16]$ to more uniform fragmenta- 


\begin{tabular}{|c|c|c|c|c|c|c|}
\hline \multirow[t]{2}{*}{ Property } & \multicolumn{2}{|l|}{ Granite } & \multicolumn{2}{|l|}{ Mortar } & \multicolumn{2}{|c|}{ Damping } \\
\hline & Mean & Std & Mean & Std & Mean & Std \\
\hline UCS [MPa] & 171.50 & 9.00 & 27.70 & 1.10 & - & - \\
\hline Brazilian tensile strength [MPa] & 10.85 & 1.52 & 2.90 & 0.49 & - & - \\
\hline Density $\left[\mathrm{g} / \mathrm{cm}^{3}\right]$ & 2.70 & 0.01 & 1.66 & 0.01 & 2.12 & 0.08 \\
\hline Porosity [\%] & 0.5 & - & 30 & - & \multicolumn{2}{|c|}{ Water saturated } \\
\hline Average grain size $[\mathrm{mm}]$ & $1-3$ & - & 0.1 & - & - & - \\
\hline Young's modulus [GPa] & 65.30 & 0.83 & 12.20 & 0.31 & - & - \\
\hline${ }^{\text {a} D y n a m i c ~ Y o u n g ' s ~ m o d u l u s ~[G P a] ~}$ & 54.12 & - & 14.51 & - & 13.65 & - \\
\hline Poisson's ratio [-] & 0.24 & 0.02 & 0.23 & 0.05 & - & - \\
\hline${ }^{\text {a} D y n a m i c ~ P o i s s o n ' s ~ r a t i o ~[-] ~}$ & 0.25 & - & 0.17 & - & 0.37 & - \\
\hline P-wave velocity $[\mathrm{m} / \mathrm{s}]$ & 4908 & 111 & 3069 & 62 & 1210 & 274 \\
\hline S-wave velocity [m/s] & 3212 & 150 & 2065 & 40 & 643 & 79 \\
\hline${ }^{\mathrm{a}}$ Dynamic shearing modulus [GPa] & 27.86 & - & 7.08 & - & 0.95 & - \\
\hline
\end{tabular}

${ }^{a}$ Values derived from the measurements of the $\mathrm{P}$ - and S-wave velocities

tion. When initiated, the blast loading propagates along the borehole towards a stemming plug at the frontal end face.

The cylinder is radially confined by a damping layer inside a blast chamber. The layer consists of a partlycured commercial grout mixture to improve the acousticimpedance matching of propagating stress waves and to protect the chamber. Table 1 shows measured material properties of the blast cylinders and of the damping layer.

The blast chamber (Fig. 2) includes four concrete segments, axially connected with two metal plates. The cord is inserted in the confined cylinder through an opening in the rear metal plate. The frontal metal plate firmly presses a protective polycarbonate window onto the end face to allow the filming and to reduce end-face spalling.

The filming [15] captured crack development at the end face following the detonation. The blast chamber also keeps the blast-generated crack patterns undisturbed, thus the fragmented material inside the cylinder allows further investigation of the internal fractures.

\subsection{CT Analysis}

The CT investigations took place at the Austrian Foundry Research Institute (ÖGI), Leoben. Blasted cylinders were scanned in a GE/Phoenix x|argos with a two-pole $320 \mathrm{kV}$ fan-beam X-ray tube and an NTB line detector. The tube parameters were $300 \mathrm{kV}$ and $2500 \mu \mathrm{A}$ using $\mathrm{Cu}$ and Sn prefilters of 1-mm thickness each. For every sample rotation 2622 images were recorded. The voxel size in the radial direction was set to $130 \mu \mathrm{m}$. The voxel size in the axial direction was set to $3 \mathrm{~mm}$ to increase the number of scanned cylinders and reduce the scanning time. As the initial granite-cylinder scans had shown significant noise, the volumereconstruction process included not only beam-hardening correction but also a noise-reduction filtering.

The high-resolution scanning covered 8 samples using a GE/Phoenix v|tome|x with a $240 \mathrm{kV}$ micro-focus cone- beam X-ray tube and a GE dynamic 41|100 flat panel detector with $4000 \times 4000 \mathrm{px}$. The samples were larger fragments from the blast cylinders and smaller undisturbed samples. The scanning parameters were set to $160-200 \mathrm{kV}$ and $200 \mu \mathrm{A}$ with different combination of $\mathrm{Sn}$ and $\mathrm{Cu}$ filters, resulting in different voxel sizes ranging from 60 to $120 \mu \mathrm{m}$. All parameters were chosen in dependence of sample size and thickness to be penetrated by the X-rays. The reconstruction was performed with a medium beam-hardening correction as well.

The CT-data of all samples were analysed with the software Volume Graphics Studio Max 3.2. For the cylindrical samples, the data sets were aligned to an outer best-fitted cylinder. The volume for the porosity analysis was limited to the fitted cylinder in order to avoid deviations due to open cracks or pores. The cracks and pores were segmented by setting the grey-value histogram with the iso- $50 \%$ threshold and by adapting the threshold manually where necessary. The minimal pore size for the detection was set to 8 voxels. The detected cracks were exported in the form of plane transverse and non-planar sections. The former followed the scanning resolution in the axial direction. The latter were obtained by virtually cutting and unrolling the fitted cylinder at different radii.

The transverse sections were analysed topologically [10, $14,15]$ to determine the variation in crack-pattern features along the cylinder axis. The same analysis covered the high-speed images and the post-mortem images of the end face [10]. Topological features like end nodes of the cracks (I), intersections with the blast-hole wall (TH), intersections with the outer mantle of the cylinder (TM), cross intersections $(X)$, branching/merging intersections $(Y)$, and other (complex) intersections $(R)$ were counted and plotted in ternary diagrams with the relative values of $\mathrm{I}, \mathrm{TH}+\mathrm{TM}$, and $\operatorname{Jint}(X+Y+R)$ as axes coordinates.

The transverse and non-planar sections were also used to evaluate the axial persistence of the interior cracks. The transverse sections of the blasted cylinders and the larger 
Fig. 3: CT images of selected blasted cylinders and larger fragments showing the deformation zones around the blast hole (a, b mortar, $12 \mathrm{~g} / \mathrm{m}$ (bl20 and b/21); $\mathbf{c}$, d granite, $12 \mathrm{~g} / \mathrm{m}$ PETN (bl25 and bl28.1))
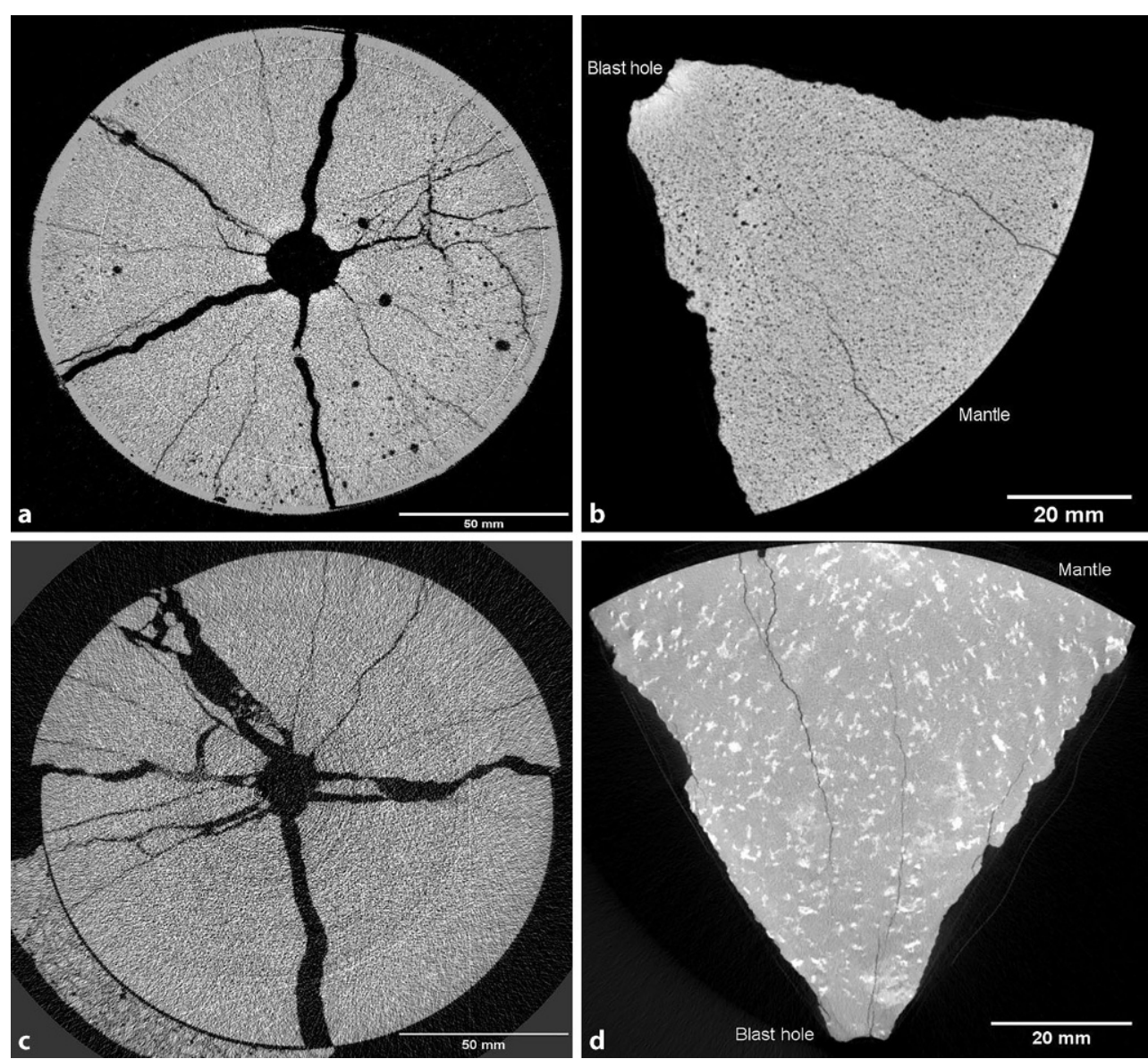

Fig. 4: The densification zone and the crushed zone (mortar $20 \mathrm{~g} / \mathrm{m}$ PETN (bl22.1)), an SEM micrograph of a thin section

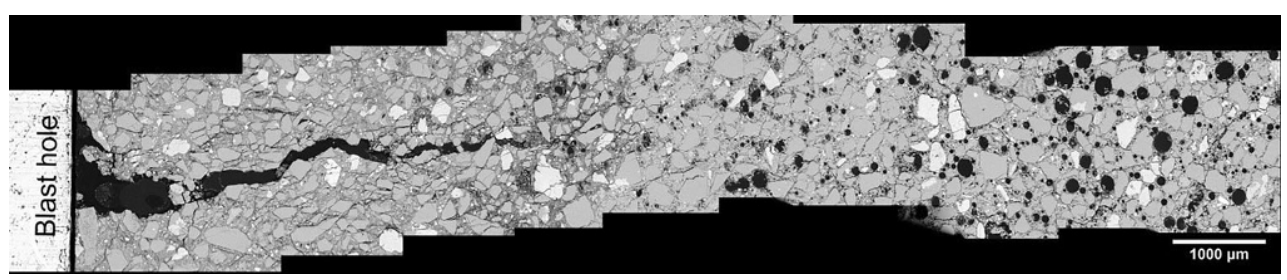

fragments were also used to evaluate different deformation zone(s) around the blast-hole wall in both materials.

The CT images of the mantle and of the interior crack surfaces were converted to a closed triangular mesh, providing many detailed STL (Stereolithography) objects. The 3D models of the larger fragments were further split into data sets for each fracture surface in MeshLab [17]. Each fracture surface was exported as a separate STL model without compression and information reduction. Finally, the fracture-surface models were analysed in CloudCompare [18] with respect to surface roughness, curvature, and topographical features.

\subsection{Microscopy}

The SEM investigations were conducted on thin sections and smaller fragments from the blast cylinders. The thin sections were cut from larger fragments of the blasted cylin- ders to cover different regions of interest: the blast hole, larger radial cracks, micro-cracks, crack tips, and crack intersections. The scanning included the smaller fragments to observe the fracture surfaces at and below the grain-size level.

\section{Results and Discussion}

\subsection{Crushed Zone and Densification Zone}

The blast-hole wall was imported into the transverse CT sections of the blast cylinders to evaluate the expansion of the blast-hole wall. This "tracing" was done in ImageJ (FIJI) [19] and used to calculate the "equivalent-circle" radius of the blast-hole for each transverse section.

The blast-hole expansion changes only slightly in the axial direction of the cylinder when not affected by the end 

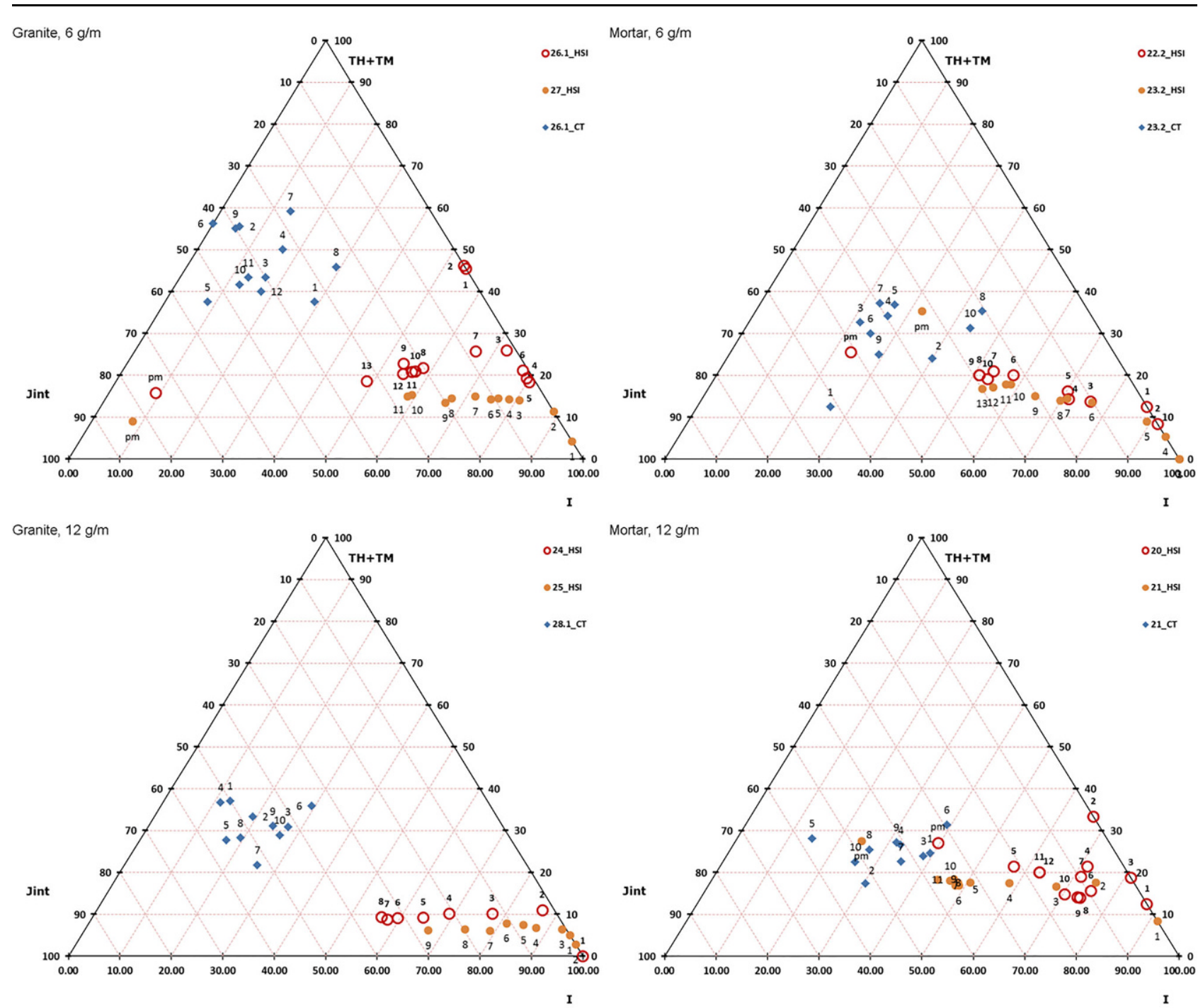

Mortar, $12 \mathrm{~g} / \mathrm{m}$

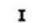

Granite, $20 \mathrm{~g} / \mathrm{m}$
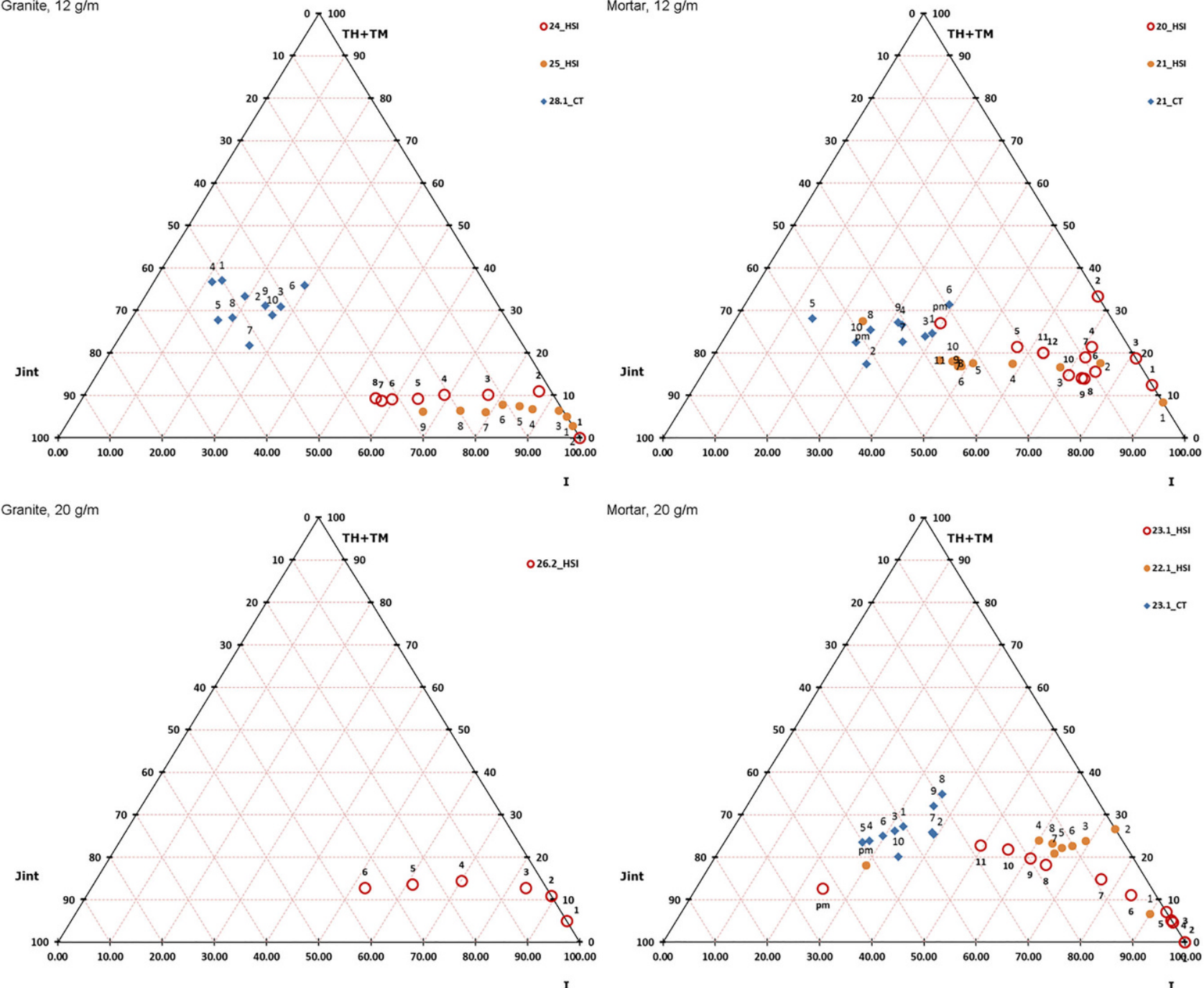

Mortar, $20 \mathrm{~g} / \mathrm{m}$

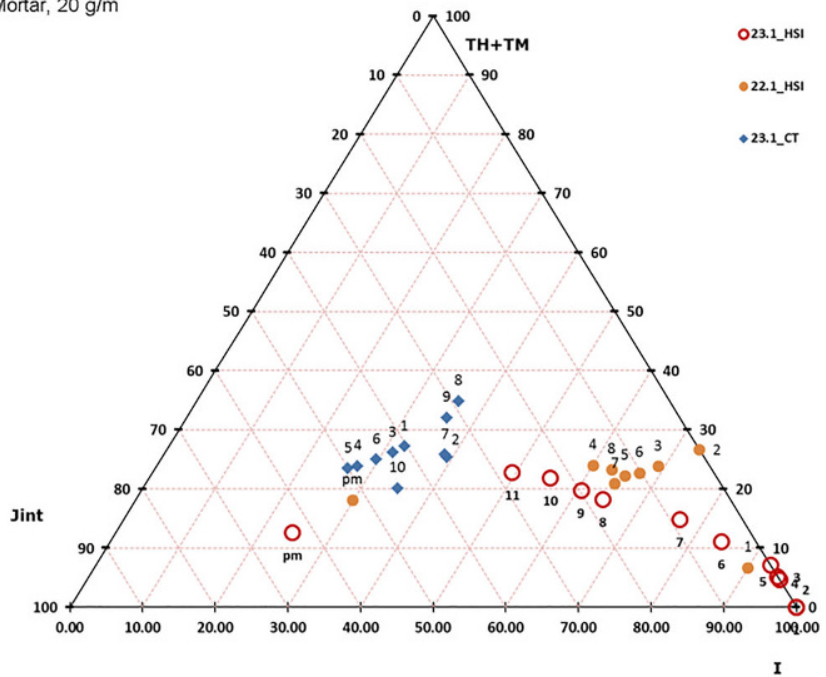

Fig. 5: Results of the topological analysis. Red and orange points represent the high-speed images with numbers indicating their time sequence with $40 \mu$ sinter-frametimeand " $p m$ " representing the post-mortem state. Blue points represent thetransverseCT sections with numbers indicating sequence in their axial position starting from the rear end face 

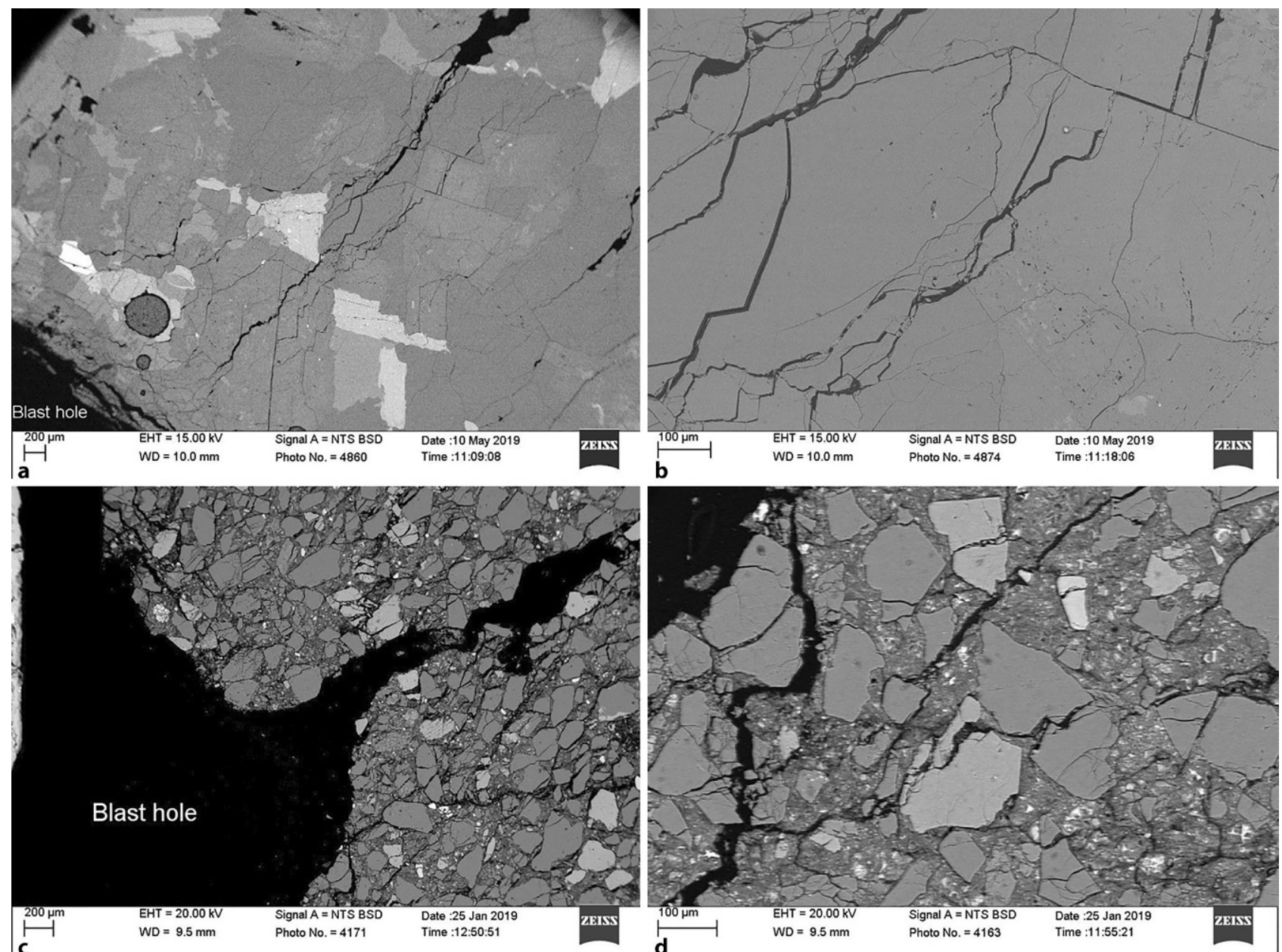

Fig. 6: Deformation zones and crack patterns near the blast hole in the thin sections (SEM images) (a, b mortar, $12 \mathrm{~g} / \mathrm{m}$ (b/20); c, d granite, $12 \mathrm{~g} / \mathrm{m}$ PETN (bl24))

faces. It increases by increasing the explosive charge, and it is higher in the granite than in the mortar.

A narrow zone around the blast-hole wall in the blasted mortar is visibly affected. This zone is of much higher density than the rest of the cylinder (Fig. 3). A crushed zone directly surrounds the densification zone in mortar. In the granite, however, the crushed zone directly surrounds the blast hole without the densification zone (Figs. 3 and 4). The densification zone thickness was measured on CT scans in ImageJ (FIJI).

These zones were also observed with SEM (Figs. 4 and 6). The micrographs show that the blast-driven crushing around the blast hole forms the densification zone mostly by deforming the pores in the cement matrix and connecting them with the ongoing fracturing, including "impact" fractures in the quartz grains. The initial porosity around the blast hole is reduced due to the shearing and crushing failure. The densification zone thickness increases with larger charge amount: $3 \mathrm{~mm}$ for $6 \mathrm{~g} / \mathrm{m}, 3.7 \mathrm{~mm}$ for $12 \mathrm{~g} / \mathrm{m}$, and $6.7 \mathrm{~mm}$ for $20 \mathrm{~g} / \mathrm{m}$.

\subsection{Crack Patterns}

The topological analysis of the transverse sections included 10 equidistant sections $(30 \mathrm{~mm})$ per scanned cylinder. The results were plotted together with those of the high-speed images (Fig. 5). The topological results from the transverse sections of both materials scatter less with larger charge amount. For mortar cylinders shots with 6 and $12 \mathrm{~g} / \mathrm{m}$ cord, the crack pattern topology data of the post-mortem endface photo lies inside the cluster of the data for the transverse sections. For granite and for mortar shots with $20 \mathrm{~g} / \mathrm{m}$ cord, this is no longer the case. One reason is the end-face spalling, which is more pronounced in the granite.

The topological features of both the transverse and the non-planar sections show high persistence, i.e., small variation in the axial direction. However, the feature count increases and both the crack paths and the spatial distributions of these features vary more with larger charge amount. This effect along with the scatter reduction in the ternary diagrams can be interpreted as a transition from "dust and boulders" to regular blast fragmentation.

The transition was also observed in the thin sections (Fig. 6). Crack wakes contain more micro-cracks and 

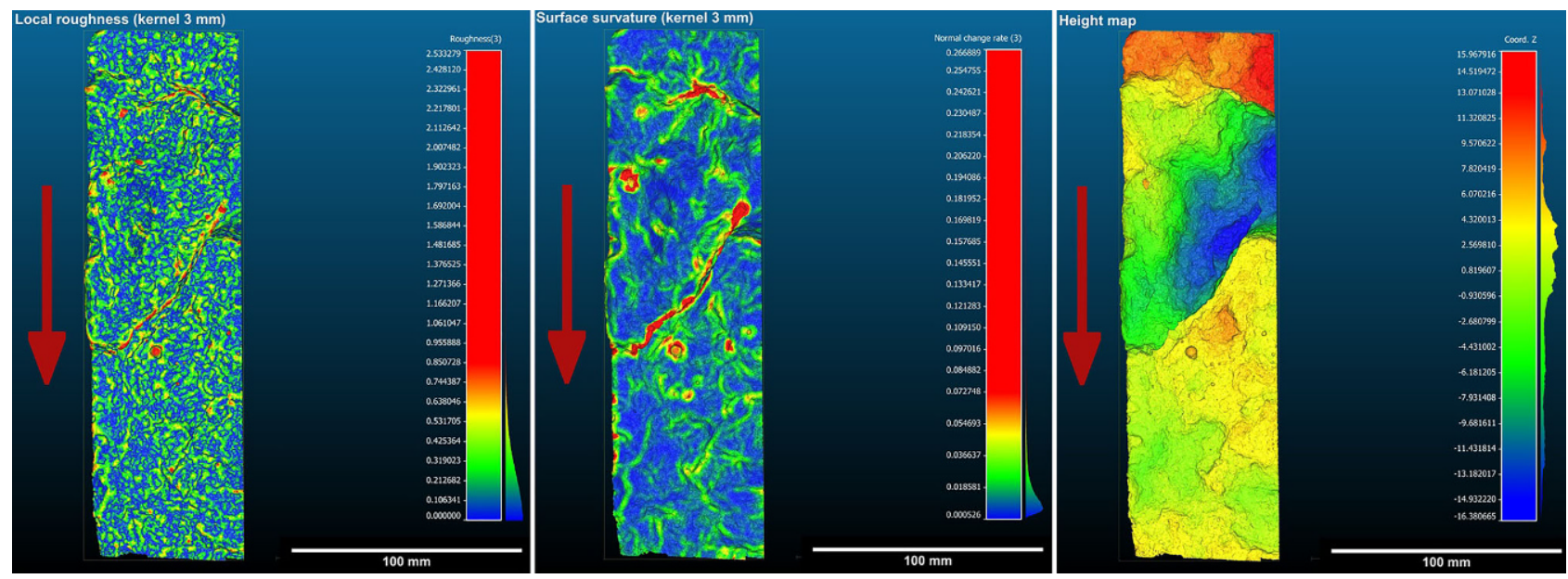

Fig. 7: Selected results of the fracture surface analysis in CloudCompare (mortar, $12 \mathrm{~g} / \mathrm{m}$ PETN (bl20))
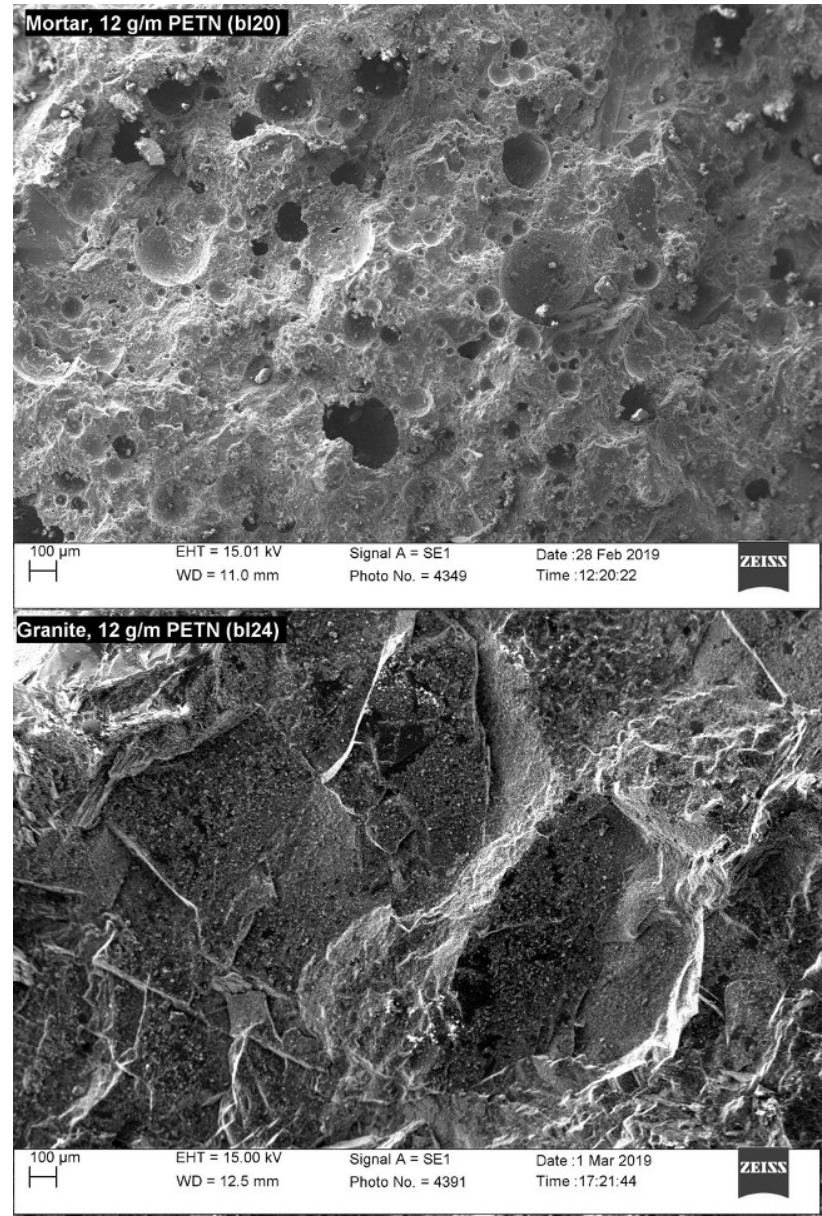

Fig. 8: Selected SEM images of fracture surfaces in small fragments

branching/merging points with larger charge amounts. The process zone (i.e., zone ahead of a crack tip) then contains more micro-cracks, composing more complex patterns (e.g., arrest marks).

The SEM scans (Figs. 6 and 8) show more transgranular fractures in the granite than in the mortar. The mortar spec- imens show mostly intergranular fractures that connect the pores in the cement matrix. Traces of other mechanisms are also present in the scans, e.g., "impact" cracks, en-echelon cracks, grain shielding, grain splitting, and grain-boundary crack arrest. These mechanisms could be interpreted as variations of the branching/merging mechanism.

\subsection{Blast-Generated Fracture Surfaces}

The larger fragments were used for fracture surface scanning. The fragments include the blast hole, the mantle, and at least one end face of the cylinder. The cropped models of the fracture surfaces were sampled into point clouds with about $10^{6}$ points. Each point cloud was then best-fitted to a plane that was used to obtain the position and orientation of the fracture surface. The inverse of this matrix was used to "reorient" the point-cloud model into the now "best-fit" $x-y$ plane. Height maps, local roughness maps, and curvature (normal change rate) maps were calculated with a kernel size of $3 \mathrm{~mm}$. Finally, the results (Fig. 7) were exported as colour-coded images based on histograms of the result data and their spatial distribution, with a red arrow indicating the blast-hole position and the detonation direction.

The height maps and the curvature maps show distinct ridges and valleys, perhaps indicating changes in the fracture propagation due to the branching/merging mechanism. Statistical analysis of the surface curvature and roughness shows no significant variation in the curvature and the roughness results.

However, the SEM images do show that the surface roughness decreases with the increase of the charge amount [14]. Also, the fracture surfaces in the mortar and the granite are different (Fig. 8), mostly due to effects of the material structure. 


\section{Conclusions}

The project studied mechanisms behind blast-induced fines focussing on the branching/merging mechanism and this has added insight into the process.

The CT-analyses and thin-section observations show more intensive fracturing in the crushed zone around the blast hole in mortar including the densification zone closest to the blast-hole wall. The densification-zone thickness increases when a larger charge amount is used. This fracturing gets more intense with increasing charge. It is also more pronounced in the granite than in the mortar.

The crack patterns in the high-speed images show a clear development, including crack branching and merging. The respective data points tend to converge to the middle area of the ternary diagram with increasing lapsed time. The topology points of the post-mortem frontal end face fit into this area when no significant spalling occurs at the end face. These points also tend to indicate more branching/merging than the dynamic points and they are located more towards the left side of the graph.

The topological analysis of the transverse CT sections indicates smaller variations in the data points when the charge is larger. These variations, i.e., scattering of the data points, are an inverse measure of persistence of the topological features along the cylinder axis. In mortar charged with 6 or $12 \mathrm{~g} / \mathrm{m}$ cord the data points for the interior transverse CT sections roughly surround the convergence point of the high-speed images. This proves that the high-speed images correctly depict the crack development, at least in a topological sense, up to about $400 \mu$ s after the detonation. The number of branching/merging intersections increases with a larger charge amount and it is larger in the granite than in the mortar.

The crack patterns do not change significantly in the axial direction of the cylinder, except near the end-faces where the boundary conditions are different. An increase of the charge provides more branching/merging points in the CT sections.

Blast-generated fracture surfaces show ridges, valleys, and other topographical features. Sharp ridges can be interpreted as macroscopic branching/merging lines. The ridges appear to be oriented at a specific angle, suggesting a possible relation between the main fracture development and the blast-wave propagation.

The SEM observations of the granite samples show at high resolution more complex and more transgranular fracturing than in the mortar sections. The crack propagation and fracture distribution in the mortar depend less on the grain size, shape, and orientation than in the granite. The reason is the influence of the cement matrix and its porosity. The observations have shown several mechanisms that could be interpreted as variations of the branching/merging mechanism on the sub-1-mm scale. This would correlate with the kink position and the fines region below in the $\mathrm{s}-\mathrm{n}(\mathrm{s})$ curves obtained from the combined mechanical and laser sieving of blasted cylinders down to $2 \mu \mathrm{m}[14,20]$.
Acknowledgements. The authors would like to thank Prof Heinrich Mali, Prof Andreas Böhm, and Prof Reinhard Pippan for their help in the research and for fruitful discussions.

Funding. The project was funded by Austrian Science Fund (FWF): P27594-N29.

Funding. Open access funding provided by Montanuniversität Leoben.

Open Access This article is distributed under the terms of the Creative Commons Attribution 4.0 International License (http://creativecommons. org/licenses/by/4.0/), which permits unrestricted use, distribution, and reproduction in any medium, provided you give appropriate credit to the original author(s) and the source, provide a link to the Creative Commons license, and indicate if changes were made.

\section{References}

1. Moser, P.: Less fines in aggregate and industrial minerals production - results of a European research project, in: Holmberg, R. (ed.): Proceedings of 3rd EFEE World Conference on Explosives and Blasting, England: EFEE, 2005, pp 567-574

2. Ouchterlony, F.; Sifferlinger, N. A.; Brechelmacher, A.: Das europäsiche Horizon 2020-Forschungsprojekt „Sustainable Low Impact Mining - SLIM“, BHM Berg- und Hüttenmännische Monatshefte, 163 (2018), Nr. 2, pp 52-56

3. Sanchidrián, J. A.: SLIM: Technology for blasting to improve mining. In: Schunnesson, $\mathrm{H}$.; Johansson, D. (eds.): Proceedings of 12th International Symposium on Rock Fragmentation by Blasting, Luleå, Sweden, 2018, Luleå Univ. of Technology 2018, pp 783-793

4. Ouchterlony, F; Moser, P.: On the branching-merging mechanism during dynamic crack growth as a major source of fines in rock blasting. In: Singh, P. K.; Sinha, A. (eds.): Rock Fragmentation by Blasting, Proceedings of 10th International Symposium on Rock Fragmentation by Blasting, USA, Boca Raton (u.a.): CRC Press, 2012, pp 65-75

5. Steiner, H. J.: The significance of the Rittinger equation in presentday comminution technology, in: Proceedings of 17th International Mineral Processing Congress Dresden 2991, Freiberg: Bergakademie, vol 1, 1991, pp 177-188

6. Thornton, D.: Kanchibotla, S. S.; Brunton, I.: Modelling the impact of rockmass and blast design variation on blast fragmentation, in: Marton, A. (ed.): Proceedings of Explo 2001 Conference, Carlton: AusIMM, 2001, pp 197-205

7. Esen, S.; Onederra, I.; Bilgin, H. A.: Modelling the size of the crushed zone around a blasthole, International Journal of Rock Mechanics and Mining Sciences 40(2003), pp 485-495

8. Onederra, I.; Esen, S.; Jankovic, A.: Estimation of fines generated by blasting-applications for the mining and quarrying industries, Transactions of the Institute of Mining and Metallurgy A, Mining Technology, London: Taylor and Francis, A113 (2004), pp A1-A11

9. Svahn, V.: Generation of fines in bench blasting, Lic. thesis, Gothenburg, Chalmers Univ. Technology, Dept. of Geology, Publication A104, 2003

10. Kukolj, I.; Iravani, A.; Ouchterlony, F: Using small-scale blast tests and numerical modelling to trace the origin of fines generated in blasting, BHM Berg- und Hüttenmännische Monatshefte, 163 (2018), Nr. 10, pp 427-436

11. Ziegler, M.: Fractography of rock joints with special emphasis on granitic rocks, Draft manuscript of PhD thesis, Dept. of Engineering Geology, ETH Zurich, Switzerland, 2010

12. Åström, J. A.; Ouchterlony, F; Linna, R. P.; Timonen, J.: Universal dynamic fragmentation in D dimensions, Physical review letters 92 (2004), Nr. 24, pp 245506-1/4

13. Åström, J. A.: Statistical models of brittle fragmentation, Advances in Physics 55(2006), Nr. 3-4, pp 247-278.

14. Kukolj, I.: Dynamic crack propagation as a source of fines in rock blasting, Draft manuscript of PhD thesis, Chair of Mining Engineering and Mineral Economics, Montanuniversitaet, Leoben, 2019

15. Kukolj, I.; Iravani, A.; Ouchterlony, F; Weiss, C.; Lubensky, J.: Filming blast fragmentation of rock and mortar cylinders, in: Schun- 
nesson, H.; Johansson, D. (eds.): Rock Fragmentation by Blasting, Proceedings of 12th International Symposium on Rock Fragmentation by Blasting, Luleå, Sweden, 2018, Luleå Univ. of Technology, pp 483-494

16. Johansson, D.: Fragmentation and waste rock compaction in smallscale confined blasting, Lic. thesis 2008:30, Luleå: Luleå Univ. Technology, 2008

17. Cignoni, P.; Callieri, M.; Corsini, M.; Dellepiane, M.; Ganovelli, F.; Ranzuglia, G.: MeshLab: an open-source mesh processing tool, in: Scarano, V.; De Chiara, R.; Erra, U. (eds.): Eurographics Italian Chapter Conference 2008, Salerno, Italy, Eurographics 2008, ISBN 978-3905673-68-5, pp 129-136
18. CloudCompare (version 2.6.3) [GPL software], http://www. cloudcompare.org/. Accessed: 22.05.2019

19. Rueden, C. T.; Schindelin, J.; Hiner, M. C.: ImageJ2: ImageJ for the next generation of scientific image data, BMC Bioinformatics 18:529, PMID 29187165, (on Google Scholar), 2017

20. Iravani, A.; Åström, J. A.; Ouchterlony, F.: Physical origin of the fine-particle problem in blasting fragmentation, Physical Review Applied, 10 (2018), iss. 3, pp 034001:1-8

Publisher's Note. Springer Nature remains neutral with regard to jurisdictional claims in published maps and institutional affiliations. 